\title{
Papular Urticaria: A Known Early Indicator of Atopic Dermatitis
}

\author{
Dr. Jayakar Thomas ${ }^{1 *}$ and Dr. Deepthi Ravi ${ }^{2}$ \\ ${ }^{1}$ Professor \& Head, Department of Dermatology, Sree Balaji Medical College, and Hospital, India \\ ${ }^{2}$ Senior Resident, Department of Dermatology, Sree Balaji Medical College, and Hospital, India
}

Submission: September 08, 2017; Published: January 24, 2018

*Corresponding author: Jayakar Thomas, Professor \& Head, Department of Dermatology, Sree Balaji Medical College, and Hospital, India, Email: jayakarthomas@gmail.com

\begin{abstract}
Papular urticaria is a common disorder occurring due to a hypersensitivity reaction secondary to bites of insects such as mosquitoes, bed bugs, fleas and ticks. It usually presents as pruritic recurrent papules or vesicles with different degrees of surrounding edema [1] and a central punctum. It has been updated earlier that papular urticaria is an early marker of atopic march. In this article we review the possible cascade of events by which papular urticaria (Insect bite reaction) could trigger the cascade of events leading to atopic diathesis.
\end{abstract}

Keywords: Papular urticaria; Atopy; Atopic dermatitis

\section{Introduction}

Papular urticaria also known as insect bite hypersensitivity develops as a result of a hypersensitivity reaction to the bites of arthropods such as mites, mosquitoes, fleas, spiders, ticks, caterpillars and bed bugs [2]. Children, non-locals, adult males and individuals from urban and periurban areas are more prone to develop papular urticaria [3]. The insect depends on the geographic area of the patient [4].

The characteristic presentation is pruritic recurring papules or papulo vesicles with different degrees of edema. The lesions are present in groups over both the exposed and covered areas of the patient. Erosions and even ulceration can result from scratching the lesions. Pyoderma may also be seen. The severity varies with the host reaction to the salivary protein.

It has been reported that papular urticaria is an early marker of the atopic march which includes atopic dermatitis, allergic rhinitis and asthma. Here we will discuss the series of events through which papular urticaria could trigger the events leading to atopic diathesis.

\section{Mechanism of Papular Urticaria}

It has been proven in a study that the absolute eosinophil count (AEC) and the serum IgE levels were elevated in all patients presenting with papular urticaria and tested for the above parameters [1].

Another study revealed a predominant CD4+ positive $\mathrm{T}$ cells, eosinophil rich infiltrate and increased IgE response which suggests a T-helper 2 (T-h2) mediated response to the salivary protein [5]. Moreover atopic individuals have a high IgE production and a persistent T-h2 response [6,7].

Another proposed mechanism is that some of the molecules in the skin such as collagen combine with the flea antigens to form adjuvants which may cause a hypersensitivity reaction in a susceptible individual [8].

The patients affected with papular urticaria have increased expression of molecules such as CD83, CD86 and HLA-DR which are related to antigen presentation and there are lower levels of regulatory cytokines such as interleukin-6 (IL-6) and IL-10. This favors the production of T-h2 pro inflammatory cytokines which are also increases in atopic diathesis and thus leads to the generation and maintenance of a skin allergic reaction caused by a childhood flea bite [9].

The allergic reaction usually develops to allergens in the saliva [10].There are five stages of the reaction [11]. Initially there is a phase in which there is no reaction (Stage 1). This is followed by a delayed type of hypersensitivity reaction indicated by a papule formation (Stage 2). Following this an immediate type of hypersensitivity reaction occurs indicated by a wheal and caused by IgE (Type I hypersensitivity). In the third phase there is a concurrent existence of the delayed and immediate type of hypersensitivity reaction. Then the delayed reaction which is cell mediated disappears and only immediate type of hypersensitivity is seen in the fourth stage. It is then followed by disappearance of the immediate type reaction and a phase of no reaction (Stage 5).

Histopathology generally reveals mild spongiosis, acanthosis and sub epidermal edema, lymphocyte exocytosis, erythrocyte 
extravasation and superficial and deep inflammatory infiltrate composed to eosinophils, neutrophils and lymphocytes [12].

The disease is more common in children though adults may also be affected and usually history of atopy in the patient or family members is present. $70 \%$ of the individuals with papular urticaria had history of atopy in a study [1]. Children eventually outgrow the disease due to desensitization after multiple exposures [13]. But further changes such as atopic dermatitis, allergic rhinitis or asthma may develop in the future as a part of atopic march which could have been possibly prevented by giving the patients antihistamines for a long period of time as is done in case of atopic dermatitis to prevent progression of the atopic march.

\section{Conclusion}

Papular urticaria is caused by both immediate (Type I, IgE mediated) and delayed type (Type IV, cell mediated) of hypersensitivity reaction.

Most of the patients of papular urticaria have history of atopy. There is a common T-h2 immune response, increased IgE levels and increased absolute eosinophil count in both atopic dermatitis and papular urticaria. This indicates the importance of asking history of atopy in patients with papular urticaria.

Papular urticaria can be considered to be a precursor of atopic diathesis and appropriate treatment at this stage along with a long term course of antihistamines may help to prevent the progression of atopic march.

\section{References}

1. Jayakar T, Selva PSK, Manoharan D, Ashok KN, Cynthia S, et al. (2014) Papular urticaria- An early of atopic march. Sudanese Journal of Dermatology 8(2): 53-57.

2. Demain JG (2003) Papular urticaria and things that bite in the night. Curr Allergy Asthma Rep 3(4): 291-303.
3. Raza N, Lodhi M S, Ahamed S, Dar NR, Ali L (2008) Clinical study of papular urticaria. J coll Physicians Surg Pak 18(3): 147-150.

4. Howard R, Frieden IJ (1996) Papular urticaria in children. Pediatr Dermatol 13(3): 246-249.

5. García E, Halpert E, Rodríguez A, Andrade R, Fiorentino S, et al. (2004) Immune and histopathologic examination of flea bite-induced papular urticaria. Ann Allergy Asthma Immunol 92(4): 446-452.

6. Neaville WA, Tisler C, Bhattacharya A, Anklam K, Gilbertson-White S, et al. (2003) Developmental cytokine response profiles and the clinical and immunologic expression of atopy during the first year of life. J Allergy Clin Immnunol 112(4): 740-746.

7. Yabuhara A, Macaubas C, Prescott SL, Venaille TJ, Holt BJ, et al. (1997) TH2-polarized immunological memory to inhalant allergens in atopics is established during infancy and early childhood. Clin Exp Allergy 27(11): 1261-1269.

8. Benjamin E, Feingold BF, Kartman L (1960) Allergy to flea bites. III. The experimental induction of flea bite sensitivity in guinea pigs by exposure to flea bites and by antigen prepared from whole flea extracts of Ctenocephalides felis felis. Exp Parsitol 10(2): 214-222.

9. Culler A, Garcia E, Rodiriguez A, Halpert E, Gómez A (2007) Functional Dysregulation of Dendritic Cells in Patients With Papular Urticaria Caused by Fleabite. Arch Dermatol 143(11): 1415-1419.

10. Peng Z, Beckett AN, Engler RJ, Hoffman DR, Ott NL, et al. (2004) Immune responses to mosquito saliva in 14 individuals with acute systemic allergic reactions to mosquito bites. J Allergy Clin Immunol 114(5): 1189-1194.

11. Oka K, Ohtaki N (1989) Clinical observations of mosquito bite reactions in man: a survey of the relationship between age and bite reaction. J Dermatol 16(3): 212-219.

12. Jordaan HF, Schneider JW (1997) Papular urticaria: A histopathologic study of 30 patients. Am J Dermatopathol 19(2): 119-126.

13. Steen C J, Carbonaro PA, Schwartz RA (2004) Arthropods in Dermatology. J Am Acad Dermatol 50(6): 819-842.

\section{Your next submission with Juniper Publishers will reach you the below assets}

- Quality Editorial service

- Swift Peer Review

- Reprints availability

- E-prints Service

- Manuscript Podcast for convenient understanding

- Global attainment for your research

- Manuscript accessibility in different formats

( Pdf, E-pub, Full Text, Audio)

- Unceasing customer service

Track the below URL for one-step submission

https://juniperpublishers.com/online-submission.php 